\section{Experimental Modelling of Local Heat Transfer Process for a Gas-liquid System in an Agitated Vessel with the System of A 315 - RT Impellers}

\author{
I. Bielka, M. Cudak, and J. Karcz*
}

West Pomeranian University of Technology in Szczecin, Department of Chemical Engineering, Szczecin, Poland

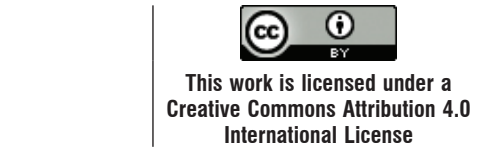

doi: 10.15255/CABEQ.2018.1392

Original scientific paper

Received: May 30, 2018

Accepted: September 17, 2018

The results of the experimental studies of the local heat transfer process for a gas-liquid system in the region of the cylindrical wall of baffled agitated vessel equipped with the system of A 315 (lower) - RT (upper) impellers are presented. Newtonian liquids of different physical properties and air were used as continuous and dispersed phases, respectively. Local heat transfer coefficients were measured using both thermal and electrochemical methods. Distributions of the heat transfer coefficients were described by means of equations (13) - (16) and (17) - (21), separately, for turbulent and transitional ranges of the fluid flow in the agitated vessel. These equations, concerning both coalescing and non-coalescing gas-liquid systems, have no equivalent in the open literature. Moreover, the results for the A 315 - RT impeller system were compared with our previous heat transfer data obtained using CD 6 - RT or RT - RT impeller systems.

Keywords:

agitation, gas-liquid system, local heat transfer, system of A 315 - RT impellers

\section{Introduction}

Mechanical agitation is one of the important unit operations often occurring in process engineering. The main role of agitation is intensification of the momentum, mass and heat transfer processes in liquids or multiphase systems of different physical properties. Proper choice of the type of the vessel, impeller(s), baffles, and heat transfer surface area affect the process efficiency and reduction of the process costs. When maintenance of stable temperature is required in an engineering operation, heat transfer is usually the controlling process in an agitated vessel.

Problems of heat transfer in agitated vessels, including theoretical backgrounds, methods of experiments and computations, as well as obtained results have been considered in detail in the following monographs ${ }^{1-3}$ and papers ${ }^{4-6}$. The results of the mean heat transfer coefficient have been given in literature for different agitated liquids, for example: viscous fluids ${ }^{7-10}$, non-Newtonian fluids ${ }^{10-14}$ and oth$\mathrm{ers}^{15-16}$. The measurements of the local heat transfer coefficient have been also carried out for liquid ${ }^{17-21}$, gas-liquid $^{21-26}$, solid-liquid ${ }^{27}$ and gas-solid-liquid ${ }^{28}$ systems.

Distributions of the heat transfer coefficient on the side of the fluid in a jacketed, baffled agitated

"Corresponding author: e-mail: Joanna.Karcz@zut.edu.pl vessel strongly depend on the impeller type. This statement confirms the results of local heat transfer obtained for different single impellers, (for example, centrally located Rushton turbine ${ }^{12,18,19,29}$, six-bladed $\mathrm{PBT}^{30,31}$, Pfaudler ${ }^{32,33}$, HE $3^{23,24}, \mathrm{CD} 6^{26,27}$, four-bladed pitched paddle ${ }^{19}$ or MR210 impeller $^{19}$ and off-centred propeller ${ }^{20,33}$, HE $3^{20,34}$, A $315^{17}$ or Rushton turbine ${ }^{17}$ ) as well as for two impellers on a common shaft ${ }^{22,35-37}$.

Proper choice of the impeller for a given task depends on the type of the physical system produced in the agitated vesse ${ }^{38-41}$. Impellers of modified blade shape are recommended in literature ${ }^{42-44}$ for the agitation of the gas-liquid system. Specifically, the CD 6 impeller (Smith turbine) should be considered for use when gas bubbles are dispersed in liquid phase $\mathrm{e}^{42,44-46}$.

In the case of processes occurring in gas-liquid systems, it would be justified to use the agitated vessel of aspect ratio $H / T$ higher than standard, i.e., $H / T>1$. Thus, the gas introduced to the vessel is better utilized ${ }^{47-49}$, however, the problem of uneven dispersion of gas bubbles in a liquid may appear. The zone of good mixing is observed near the impeller, whereas the regions of different gas content in a liquid are formed in other parts of the agitated vessel. This problem can be solved partially by adding a second impeller on the shaft. In the agitated vessel with two impellers, gas dispersion in a liquid improves, but energy consumption of the process increases. The choice of the proper system of im- 
pellers is an important problem. Circulation of the fluid in a vessel depends on the type of impellers, number of impellers, and their interaction. In a system with multiple impellers, the lower impeller should initiate dispersion of gas bubbles in the liquid, whereas the upper impeller should maintain the gas dispersion in the other part of the agitated vessel. Within the area of agitation of gas-liquid systems, impellers of modified blade shape, such as CD 6 or A 315 should be considered because of good gas dispersion in a liquid (CD 6) and production of lower shear stress in the fluid (A 315).

Karcz and Bielka ${ }^{37}$, studying the heat transfer process in a baffled agitated vessel with two impellers on a common shaft, proposed the following dimensionless equation to calculate averaged heat transfer coefficient

$$
N u_{\mathrm{m}}=\left[\frac{\alpha T_{\mathrm{o}}}{\lambda}\right]_{\mathrm{m}}=C_{\mathrm{m}} \operatorname{Re}^{A} \operatorname{Pr}^{0.33} V i^{0.14} f\left(F r_{\mathrm{g}}\right)
$$

where $F r_{\mathrm{g}}=w_{\mathrm{og}}{ }^{2} / g T, m$ denotes averaged value. Eq. (1) describes three different systems of two impellers on a common shaft (RT - RT; CD 6 - TR; A 315 - RT, where RT is upper impeller) used to agitate unaerated or aerated Newtonian liquids of low or high viscosity. For the liquid phase and both turbulent and transitional ranges of fluid flows, the highest values of coefficient $C_{\mathrm{m}}$ corresponded to the system of double Rushton turbines, and the lowest values corresponded to the system with lower A 315 and upper RT impeller. The values of exponent $A$ in Eq. (1) are higher for the turbulent fluid flow (Newtonian liquid of low viscosity) than that obtained for the transitional fluid flow (Newtonian liquid of high viscosity).

When the results of the heat transfer coefficients are completed additionally with the data of power consumption $P$ for a given geometry of the agitated vessel, then it is possible to evaluate the efficiency of the heat transfer process. Karcz et al. ${ }^{50}$ proposed the following modified equation correlating mean values of the heat transfer coefficients with the specific power consumption $P / V$

$$
\begin{aligned}
N u_{\mathrm{m}} & =(\pi / 4)^{A / 3} K\left(\operatorname{Re}_{P, V}\right)^{A / 3} \operatorname{Pr}^{0.33} V i^{0.14}= \\
& =C_{p}\left(\operatorname{Re}{ }_{P, V}\right)^{A / 3} \operatorname{Pr}^{0.33} V i^{0.14}
\end{aligned}
$$

where modified $R e$ number is defined as follows

$$
\operatorname{Re}_{P, V}=\frac{\left(\frac{P}{V}\right) T_{\mathrm{o}}^{4} \rho^{2}}{\eta^{3}}
$$

Comparison of the coefficients $C_{P}$ shows that the highest efficiency is characteristic for the heat transfer process in the agitated vessel with double Rushton turbines, and the lowest in the vessel with lower A 315 and upper RT impeller. Differences are not observed in the heat transfer efficiency for both liquid and gas-liquid systems agitated in vessels of identical geometry, equipped with the same system of impellers. This is caused by the decrease in both heat transfer coefficient and power consumption in the gas-liquid system compared to the liquid phase.

However, knowledge of the values of heat transfer coefficients, mean for whole wall of the agitated vessel, is insufficient because, in this way, the regions of different intensity of heat transfer cannot be identified on the heat transfer surface area. For this reason, quantitative analysis of the distributions of heat transfer coefficient in a jacketed, baffled, agitated vessel equipped with two impellers on a common shaft was carried out by $\mathrm{Karcz}^{25}$ and Bielka et al..$^{22}$

Karcz $^{25}$ performed an experimental study of the distributions of heat transfer coefficient along the wall of the tall agitated vessel equipped with a dual Rushton turbine system. The measurements were performed in a vessel of inner diameter $T=0.3 \mathrm{~m}$, filled with a liquid up to height $H=2 T$. Local heat source was used to measure heat transfer coefficient in liquid and air-Newtonian liquid systems. The obtained distributions were described mathematically in the form of the dependence $N u / \operatorname{Re}^{A} \mathrm{Pr}^{0.33} \mathrm{Vi}^{014}=$ $\mathrm{f}\left(z / H, F r_{g}\right)$ within the range of $4 \cdot 10^{4}<R e<10^{5}$; $0<F r_{\mathrm{g}}<8.8 \cdot 10^{-6} ; 0<z / H<1$. Axial profiles of heat transfer coefficients revealed the existence of two strong local maxima on the level corresponding to the height of both Rushton turbines. Moreover, the results showed a decrease in heat transfer coefficient value in the presence of the gas phase in the system. This was observed especially on the level of both Rushton turbines.

Bielka et al. ${ }^{22}$ developed experimental studies of the distributions of heat transfer coefficient on the cylindrical wall of the tall agitated vessel equipped with two high-speed impellers. The system with lower CD 6 impeller (Smith turbine) and upper Rushton turbine was used to agitate air-Newtonian liquid systems within the transitional and turbulent range of the fluid flow. The lower CD 6 impeller was selected for study because this type of impeller disperses gas phase in a liquid very well and is recommended in literature ${ }^{41,51,52}$ for agitation of gas-liquid systems. The measurements were carried out using both thermal and electrochemical measuring methods. The distributions of the heat transfer coefficient were mathematically described using the dependence $N u / \operatorname{Re}^{A} P r^{0.33} V i^{014}=\mathrm{f}\left(z / H, F r_{\mathrm{g}}\right)$. Based on the obtained results, Bielka et al. ${ }^{22}$ proved 
a)
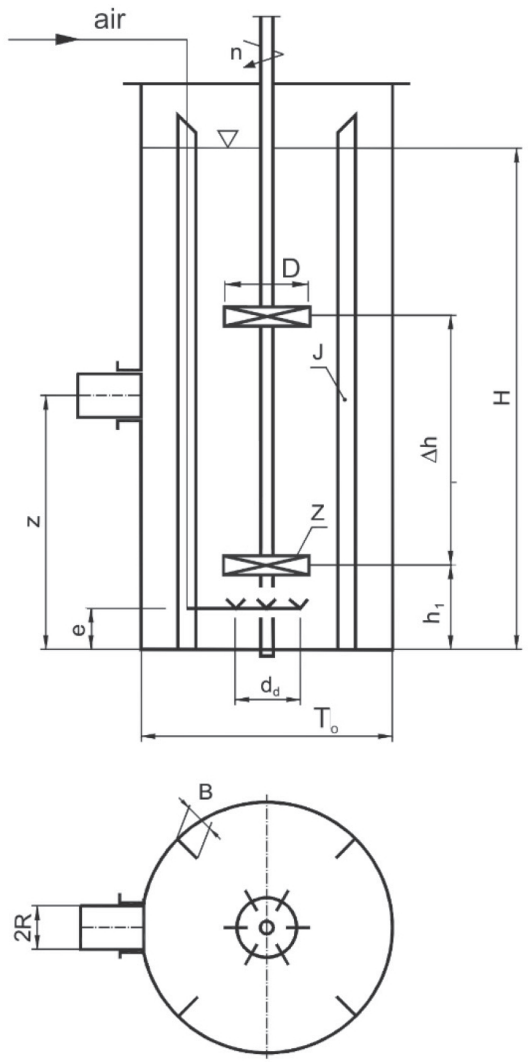

b)
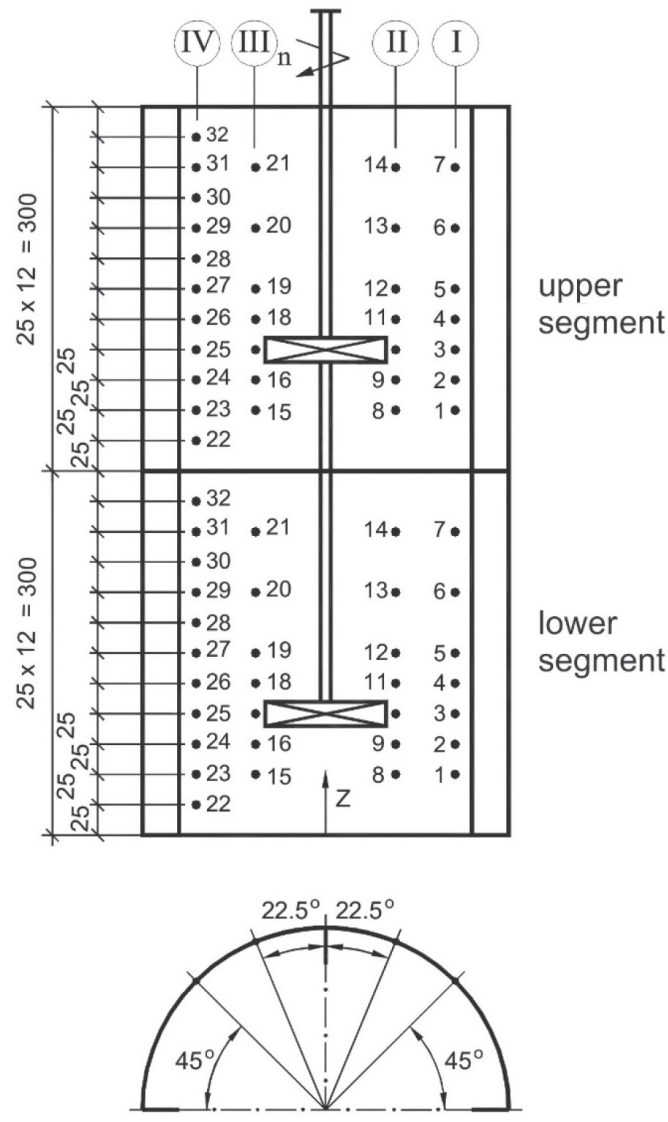

Fig. $1-a)$ Geometry of the agitated vessel used to measure heat transfer coefficient by means of thermal method; b) arrangement of the measuring points in an electrochemical method that local heat transfer coefficients have the highest values on the level of both impellers. However, local maximum corresponding to the lower CD 6 impeller has lower value than that ascribed to the upper Rushton turbine. Like the system of double Rushton turbines, the presence of the gas phase in the gas-liquid system affects the decrease in heat transfer coefficient, especially in the region of both impellers (lower CD 6 and upper RT).

The A 315 impeller (Fig. 2) has a large surface area of the four blades and produces lower shear stresses in the fluid in relation to other impellers (for example, Rushton or Smith turbines). Bakker ${ }^{51}$ stated that the flow field created by down-pumping A 315 impeller in liquid and gas-liquid systems differs from the flow fields generated by radial flow Rushton and Smith turbines. Considering the features of the A 315 impeller, it is often recommended for use in various bioprocesses.

In this study, the distributions of the heat transfer coefficient for a gas-liquid system, near the inner cylindrical wall of the agitated vessel equipped with a system of A 315 - RT impellers, were determined experimentally and described mathematical1y. Additionally, these results were compared with our previous heat transfer data obtained using CD 6 - RT or RT - RT impeller systems. The effect of the lower impeller on the intensity of heat transfer in a jacketed baffled vessel was analysed.

\section{Material and methods}

The distributions of the heat transfer coefficient $\alpha$ on the cylindrical wall of the agitated vessel were measured using two different, thermal and electrochemical, experimental methods. The measurements were carried out in a baffled agitated vessel of inner diameter $T=0.3 \mathrm{~m}$ (Fig. 1a). The flat-bottomed vessel was filled with a liquid up to height $H=2 T$. The system of two high-speed agitators of diameter $D=T / 3$, mounted on the common shaft at distances $h_{1}=0.17 \mathrm{H}$ and $h_{2}=0.67 \mathrm{H}$ from the vessel bottom, respectively, was used. The upper agitator was a radial flow Rushton turbine (Fig. 2a, number of blades $Z=6$, length of blade $a=0.25 D$, width of blade $b=0.2 D$, impeller disc diameter $d=0.75 D)$, whereas down-pumping A 315 impeller (Fig. 2b, $\left.Z=4, \beta=45^{\circ}, b=0.5 D\right)$ was located in lower position. The agitated vessel was equipped with four $(J=4)$ baffles of width $B=0.1 T$ arranged symmetrically inside the vessel. A ring-shaped gas sparger of diameter $d_{\mathrm{d}}=0.75 \mathrm{D}$ was located at distance $e=0.5 D$ from the vessel bottom.

The experiments were performed for varied impeller speeds $n$ and superficial gas velocity $w_{\text {og }}$ (where $\left.w_{\text {og }}=4 V_{\mathrm{g}} / p T_{\mathrm{o}}^{2}, 0<w_{\text {og }}\left(\mathrm{m} \mathrm{s}^{-1}\right)<6 \cdot 10^{-3}\right)$. 
a)

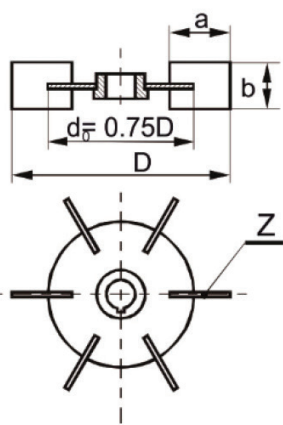

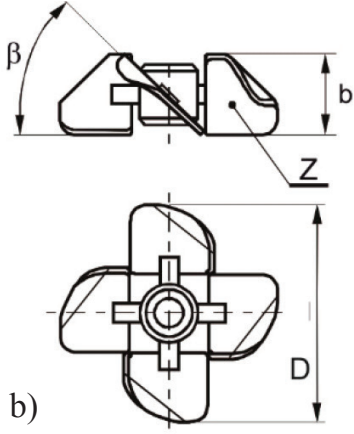

Fig. 2 - Impellers used in the study; a) Rushton turbine; b) A 315 impeller

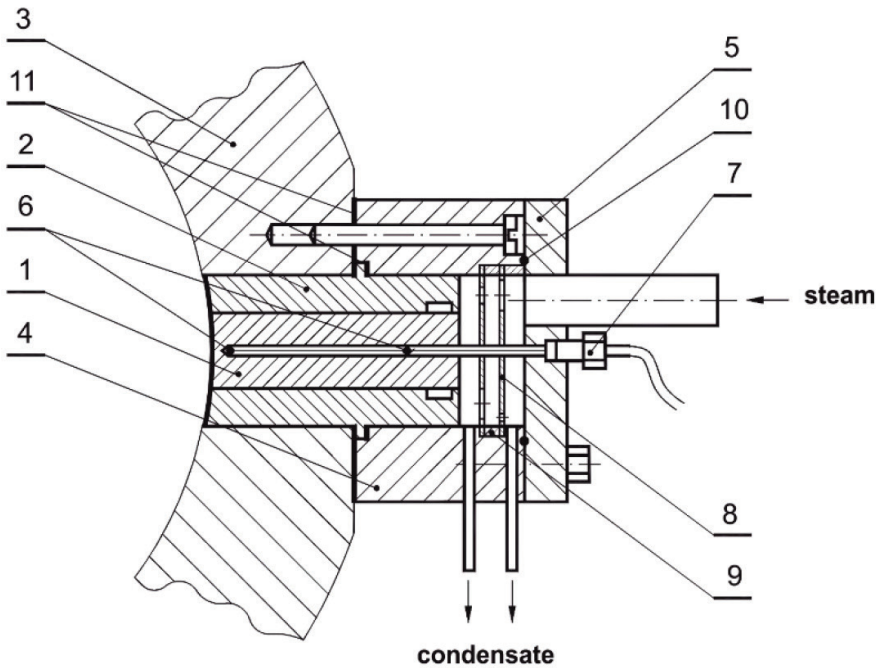

Fig. 3 - Scheme of the local heat flux meter: 1 - measuring cylindrical element; 2 - surrounding ring; 3 - wall of the agitated vessel; 4 - sleeve; 5 - cover; 6 - thermocouples; 7 gland; 8 - out dropping plates; 9 - distance ring; 10 - O-ring; 11 - silicon seal

The lowest impeller speeds used in the experiments enabled dispersion of gas bubbles underneath the lower impeller. The lowest impeller speeds were chosen experimentally due to insufficient quantitative data in literature ${ }^{53}$ for the tested system of A 315 - RT impellers. Newtonian liquids of different physical properties (distilled water, $30 \%$ aqueous solution of glucose, an electrolyte, technical glycerol) were used as continuous phase. Gas phase was air. Both types of gas-liquid systems, differing in the ability to coalesce gas bubbles, were tested: coalescing systems (with distilled water or aqueous solution of glucose), and non-coalescing systems (with technical glycerol as liquid phase).

The thermal method used in this study to measure local heat transfer coefficient was described in detail in papers ${ }^{18,22,25}$. The local heat source was built at the vessel wall at height $z$ (Fig. 1a). Seven different values of the dimensionless axial coordinate $z / H$ were taken into account, namely: $z / H=0.07,0.16,0.28,0.42,0.56,0.67$, and 0.82 . The local heat flux meter (Fig. 3) consisted of a measuring cylindrical element (1) of diameter $2 R=30 \mathrm{~mm}$, and surrounding ring (2) of diameter $60 \mathrm{~mm}$. Both elements (1) and (2), made of stainless steel, were fitted into the sleeve (4), made of polyamide. The cover (5) closed the sleeve (4) in such a way that a chamber provided with steam of temperature $102{ }^{\circ} \mathrm{C}$ was formed inside. Condensate continuously flowed out to the condenser pot. Out dropping plates (8) and distance rings (9) were located in the chamber. Plates (8) were used to separate "false" condensate produced from steam condensation on the cool walls of the housing, from the condensate obtained during the steam condensation on the back part of the measuring element. Moreover, plates (8) protected the wall of the inner block against direct blow of the steam flow. Silicon seal was used to fix sleeve (4) with the vessel wall (3), and O-ring (10) sealed the cover (5). Two $\mathrm{Fe}-\mathrm{CuNi}$ thermocouples (6) connected in narrow sleeve were located in the inner measuring block. The sleeve with thermocouples was sealed by means of the gland (7). Front thermocouple was situated nearer the contact surface of the heat flux meter with the agitated liquid. The distance between both thermocouples was $l_{1}=73 \mathrm{~mm}$, whereas the distance between front thermocouple and the contact surface of the measuring element with agitated liquid was $l_{2}=2 \mathrm{~mm}$

The values of the local heat transfer coefficient $\alpha$ were computed from the following equation

$$
\alpha=\frac{q_{\mathrm{w}}}{\Delta T}=\frac{q_{\mathrm{w}}}{T_{\mathrm{w}}-T_{\mathrm{m}}}
$$

where $q_{\mathrm{w}}$ - heat flux, $\Delta T$ - driving difference of temperature between outer wall of the measuring element $T_{\mathrm{w}}$ and agitated liquid $T_{\mathrm{m}}$. For steady-state conditions of the measurement, heat flux $q_{\mathrm{w}}=q_{1}=q_{2}$, where $q_{1}$ and $q_{2}$ denote heat flux conducted through the measuring element (1) of the heat source (Fig. 3)

$$
\begin{aligned}
& q_{1}=\frac{\lambda_{1}}{l_{1}}\left(T_{1}-T_{2}\right) \\
& q_{2}=\frac{\lambda_{1}}{l_{2}}\left(T_{1}-T_{w}\right)
\end{aligned}
$$

Assuming that $q_{1}=q_{2}$, wall temperature $T_{\mathrm{w}}$ was calculated from the equation

$$
T_{\mathrm{w}}=T_{1}\left[1-\left(\frac{l_{2}}{l_{1}}\right)\right]+\left(\frac{l_{2}}{l_{1}}\right) T_{2}
$$

Analysis of the impact of the size of the heat flux meter on the local heat transfer coefficient 
shows ${ }^{22,25}$ that temperature profile within the thermal boundary layer is stabilized for the measuring element of diameter $30 \mathrm{~mm}$, therefore, the calculated value of the $\alpha$ does not require correction.

Electrochemical measurements of the local heat transfer coefficient $\alpha$ were carried out by means of the computer-aided method. This method was described in detail in papers ${ }^{22,26,27,54}$. In an electrochemical method, diffusion current $I_{\mathrm{d}}$, proportional to the local mass transfer coefficient $k_{\mathrm{A}}$, is measured and an analogy between mass and heat transfer processes is assumed, i.e.,

$$
\alpha_{\text {anal }}=c_{p} \rho\left(\frac{S c}{P r}\right)^{2 / 3} k_{\mathrm{A}}=c_{p} \rho\left(\frac{S c}{P r}\right)^{2 / 3} \frac{I_{\mathrm{d}}}{C_{\mathrm{A}} z_{\mathrm{e}} F S}
$$

where $c_{p}, \rho$ - specific heat and density of the electrolyte, $C_{\mathrm{A}}$ - concentration of the component $\mathrm{A}$ in the electrolyte, $z_{\mathrm{e}}$ - number of electrons taking part in the reaction, $S$ - surface area of the cathode, $F$ Faraday's constant, $S c, P r-$ Schmidt and Prandtl numbers. When small electrodes are used as measuring points, the effect caused by the developing of the concentration profile in the liquid laminar boundary layer, should be considered. In order to eliminate entrance effect, the result of the measurement should be corrected by means of the calibration factor $p_{\text {corr }}$ discussed in paper ${ }^{20,4}$

$$
\alpha=\alpha_{\text {anal }} p_{\text {corr }}
$$

In computer-aided electrochemical method ${ }^{22}$, as measuring sensors, 64 nickel circular cathodes were used with a diameter $4 \mathrm{~mm}$, built into the wall of the agitated vessel (Fig. 1b). The cathodes were arranged in four columns on a quarter of the vessel wall. The sensors in the third column were located at angle position of $22.5^{\circ}$ before baffle, whereas those in the second column were at angle position of $22.5^{\circ}$ behind baffle. Clearance between sensors in the fourth column was $25 \mathrm{~mm}$. Cathodic reduction of the potassium ferricyanide $\mathrm{K}_{3} \mathrm{Fe}(\mathrm{CN})_{6}$ was employed as a measuring system. At each measuring point (Fig. 1b), the measuring digital voltage signal was sampled 200 times. Diffusion current $I_{\mathrm{d}}$ representative for a given measuring point was calculated automatically based of the averaged value from the sampling.

In the electrochemical method, a set of 1024 data was obtained, because the measurements were performed for 4 values of impeller speed $n$, and 4 values of the superficial gas velocity $w_{\mathrm{og}}$, for each of the 64 measuring points (four values of the angle coordinate and different values of dimensionless axial coordinate $z / H$ ). In the thermal method, a set of 1050 data was obtained, because the experiments were carried out for 10 values of the impeller speed $n, 5$ values of the superficial gas velocity $w_{\text {og }}, 3$ types of liquid as a continuous phase, for each of the 7 measuring points (different values of the $z / H$ ). In total, 2074 experimental values of the heat transfer coefficient were obtained using both thermal and electrochemical methods.

\section{Results and discussion}

Experimental axial distributions of the heat transfer coefficient $\alpha$ for different liquids and different Re numbers are presented in Figs. 4a, b, c. They were obtained by means of the thermal method and using agitator systems with the lower A 315 impeller and upper Rushton turbine. Turbulence of the fluid flow depends on the viscosity of the compared liquids, and it affects the heat transfer intensity. Thus, the highest values of the local heat transfer coefficient corresponded to the distilled water (lowest viscosity, highest $R e$ number, Fig. 4a), and the lowest values corresponded to glycerol (highest vis-
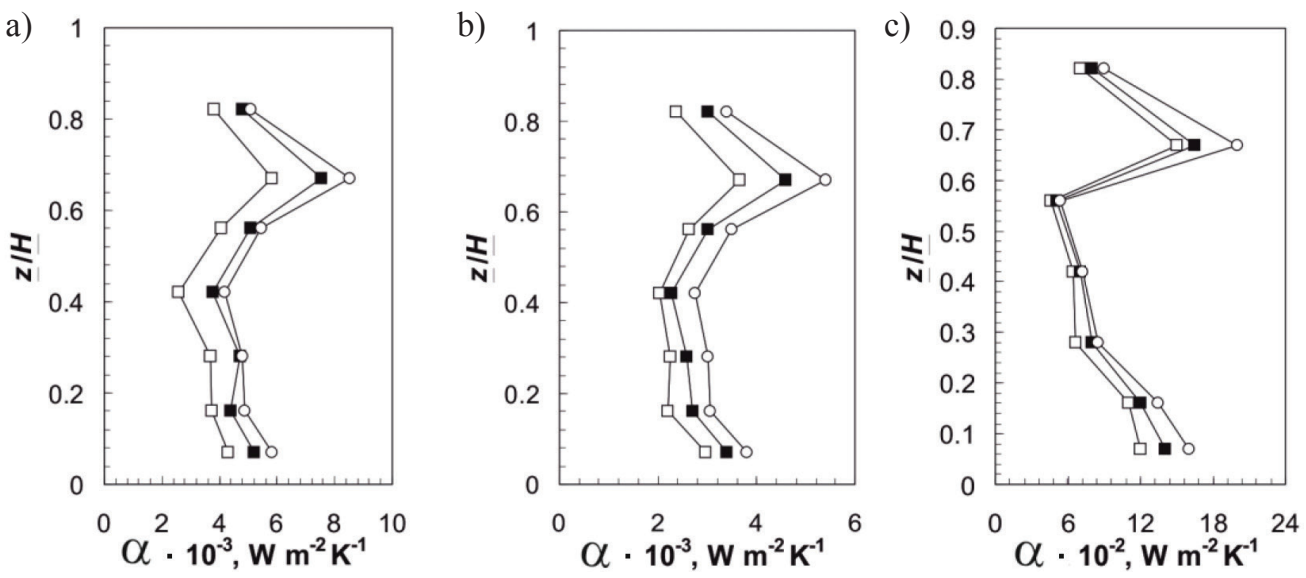

Fig. 4 - Axial distributions of heat transfer coefficient $\alpha$, Re $\neq$ const; A 315-RT; a) distilled water, $\square-\operatorname{Re}=45000$; $\mathbf{\square}-\operatorname{Re}=$ 60000; $O-R e=75000$; b) $30 \%$ aqueous solution of glucose, $\square-R e=15000$; 


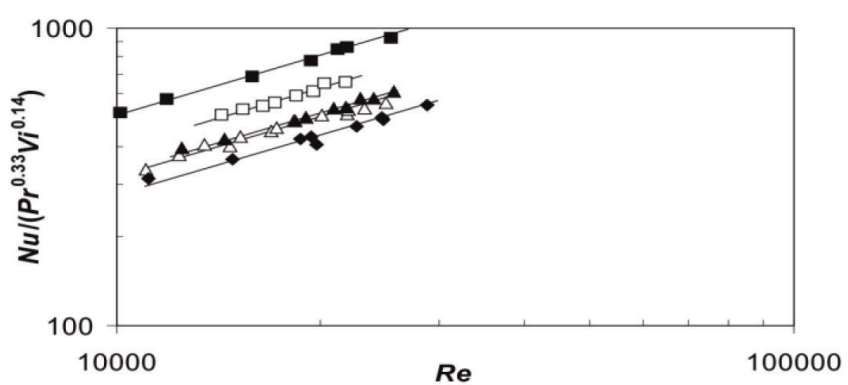

Fig. 5 - The dependence $\mathrm{Nu} /\left(\operatorname{Pr}^{0.33} \mathrm{Vi}^{0.14}\right)=f(\operatorname{Re})$ for $30 \%$ aqueous solution of glucose $\left(w_{o g}=0 \mathrm{~m} \mathrm{~s}^{-1}\right)$ and different positions of the dimensionless axial coordinate $z / H$; lower impeller $-A 315$, upper impeller $-R T, \square-z / H=0.07 ; \Delta-z / H=0.16$; $\checkmark-z / H=0.42 ; \boldsymbol{\square}-z / H=0.67 ; \boldsymbol{\Delta}-z / H=0.82 ;$ experimental points obtained using thermal method

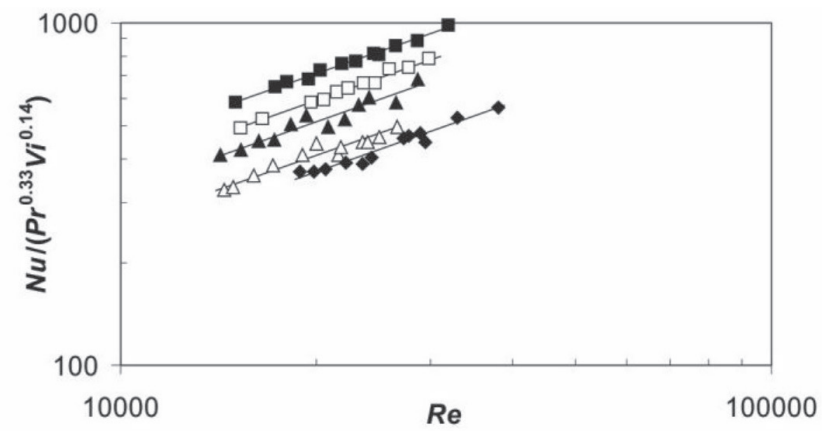

Fig. 6 - The dependence $N u /\left(\operatorname{Pr}^{0.33} \mathrm{Vi}^{0.14}\right)=f(\operatorname{Re})$ for $30 \%$ aqueous solution of glucose $\left(w_{o g}=5.1 \cdot 10^{-3} \mathrm{~m} \mathrm{~s}^{-1}\right)$ and different positions of the dimensionless axial coordinate $\mathrm{z} / \mathrm{H}$; lower impeller - A 315, upper impeller $-R T, \square-z / H=0.07 ; \Delta-z / H$ $=0.16 ;-z / H=0.42 ; \boldsymbol{\square}-z / H=0.67 ; \boldsymbol{\Delta}-z / H=0.82 ;$ experimental points obtained using thermal method

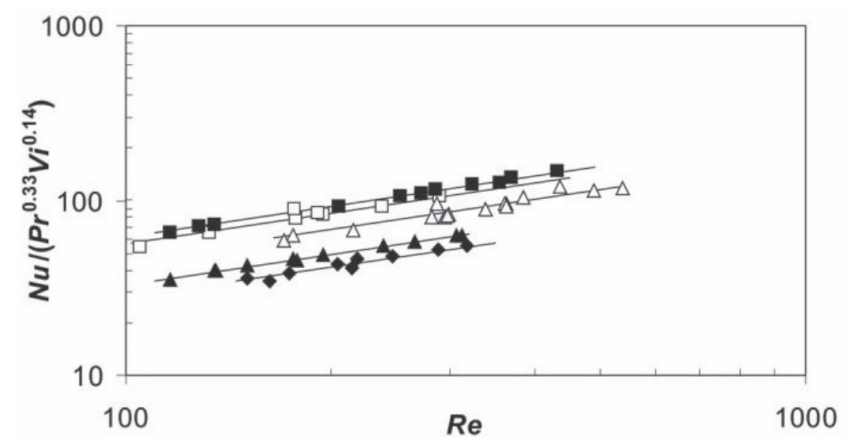

Fig. 7 - The dependence $N u /\left(\operatorname{Pr}^{0.33} V^{0.14}\right)=f(R e)$ for glycerol $\left(w_{o g}=0 \mathrm{~m} \mathrm{~s}^{-1}\right)$ and different positions of the dimensionless axial coordinate $z / H$; lower impeller $-A 315$, upper impeller $-R T$, $\square-z / H=0.07 ; \Delta-z / H=0.16 ;--z / H=0.42 ; \mathbf{\square}-z / H=$ $0.67 ; \boldsymbol{\Delta}-z / H=0.82$; experimental points obtained using thermal method

cosity, lowest Re number, Fig. 4c). Local heat transfer coefficients increased with the increase in $R e$ number (Fig. 4b) within the whole range of the dimensionless axial coordinate $z / H$. The distributions $\alpha=\mathrm{f}(z / H)$ were maximum at the level of the upper impeller $(z / H=0.67)$ - radial flow Rushton turbine. Local heat transfer at the level of the lower A 315

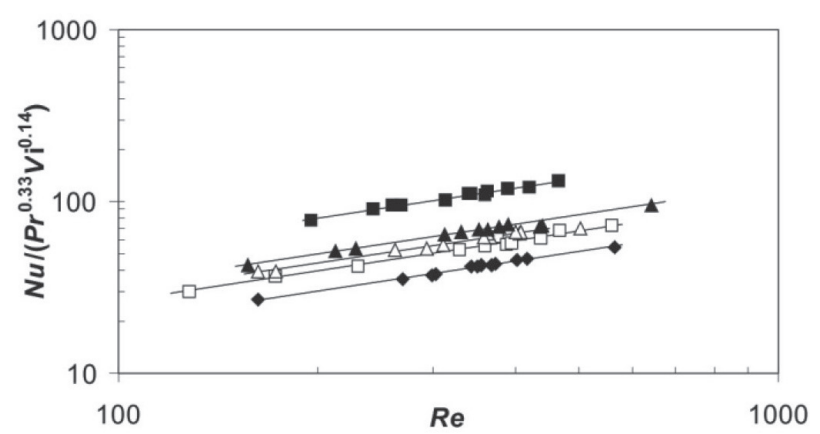

Fig. 8 - The dependence $N u /\left(\operatorname{Pr}^{0.33} \mathrm{Vi}^{0.14}\right)=f(\operatorname{Re})$ for glycerol $\left(w_{o g}=5.1 \cdot 10^{-3} \mathrm{~m} \mathrm{~s}^{-1}\right)$ and different positions of the dimensionless axial coordinate $\mathrm{z} / \mathrm{H}$; lower impeller $-A 315$, upper impeller $-R T, \square-z / H=0.07 ; \Delta-z / H=0.16 ; \diamond-z / H=0.42$; $-z / H=0.67 ; \boldsymbol{\Delta}-z / H=0.82$; experimental points obtained using thermal method

impeller $(z / H=0.17)$ was significantly less intensive compared to the data for the upper Rushton turbine.

For liquid phase and gas-liquid systems, local heat transfer coefficient $\alpha$ depends factors, such as: position on the cylindrical vessel wall (axial coordinate $z / H$ ), impeller speed $n$, physical properties of the fluid, and superficial gas velocity $w_{\mathrm{og}}$. Our experimental results of the heat transfer coefficient were calculated using the following dimensionless equation

$$
N u=\left[\frac{\alpha T_{\mathrm{o}}}{\lambda}\right]=C\left(z / H, w_{\mathrm{og}}\right) \operatorname{Re}^{A} \operatorname{Pr}^{B} V i^{E}
$$

The literature data ${ }^{3}$ values of the exponents $B=$ 0.33 and $E=0.14$ were assumed in Eq. (10). The dependences $N u /\left(\operatorname{Pr}^{0.33} V^{0.14}\right)=\mathrm{f}(R e)$ for different liquids (superficial gas velocity $w_{\mathrm{og}}=0 \mathrm{~m} \mathrm{~s}^{-1}$ ) and air-liquid systems $\left(w_{\mathrm{og}} \neq 0 \mathrm{~m} \mathrm{~s}^{-1}\right)$, as well as different positions of the dimensionless axial coordinate $z / H$ are compared in Figs. $5-8$. The data for aqueous solution of glucose as liquid phase and range of Re number $\in\left(10^{4} ; 4 \cdot 10^{4}\right)$ are shown in Figs. $5-6$. Figs. 7 and 8 illustrate the results for glycerol as liquid phase, and range of the $R e$ number varied from $10^{2}$ up to $7 \cdot 10^{2}$.

In Figs. $5-8$, the dependences $N u /\left(\mathrm{Pr}^{0.33} \mathrm{Vi}^{0.14}\right)=$ $\mathrm{f}(R e)$ are shown for the axial coordinate $z / H=0.07$, $0.16,0.42,0.67$, and 0.82 . The highest values of local heat transfer coefficient in Figs. $5-8$ correspond to the dimensionless axial coordinate $z / H=0.67$ (position of upper impeller), and the lowest values correspond to $z / H=0.42$ (position between both impellers).

On the basis of the experimental dependences

$$
\frac{N u}{\operatorname{Pr}^{0.33} V i^{0.14}}=C\left(z / H, w_{\text {og }}\right) R e^{A}
$$

shown among others in Figs. 5 - 8, the value of exponent $A$ was estimated statistically for each of 

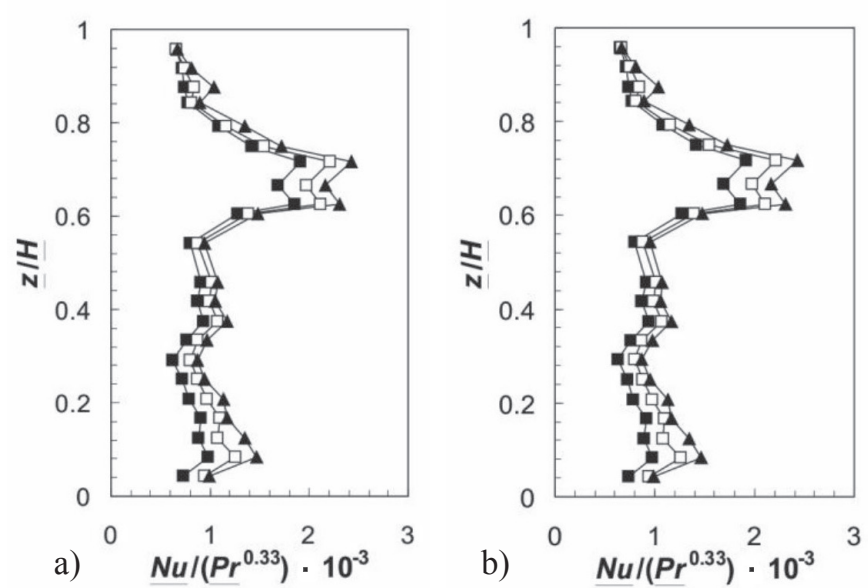

Fig. 9 - Axial distributions of heat transfer coefficient $\mathrm{Nu}$ / $\left(\operatorname{Pr}^{0.33}\right)=f(z / H)$; liquid: electrolyte; A 315 (lower) $-R T$ (upper); a) $w_{o g}=0 \mathrm{~m} \mathrm{~s}^{-1}$ b) $w_{o g}=5.1 \cdot 10^{-3} \mathrm{~m} \mathrm{~s}^{-1} ; 0-R e=30000 ; 0$

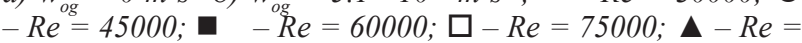
90000; experimental points obtained using electrochemical method
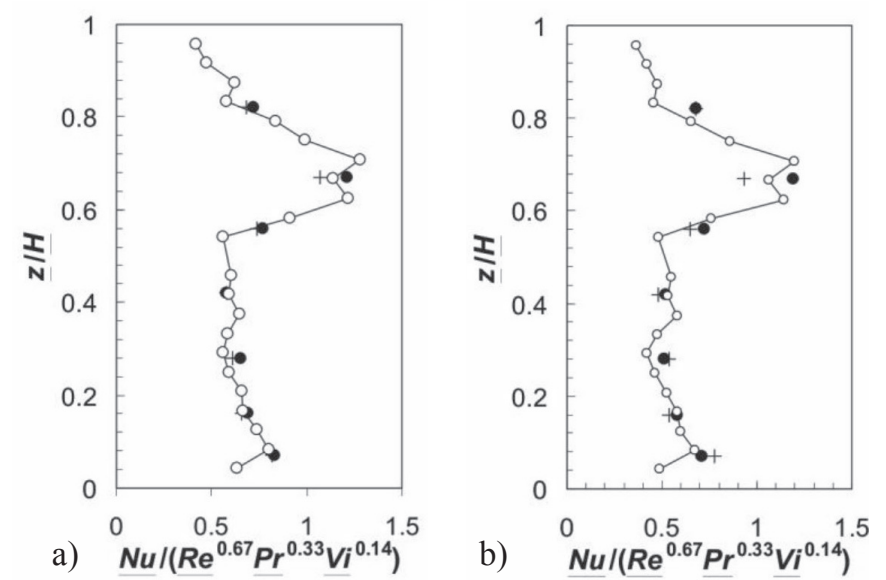

Fig. 10 - Comparison of axial distributions of the dependance $N u /\left(\operatorname{Re}^{0.67} \operatorname{Pr}^{0.33} \mathrm{Vi}^{0.14}\right)=f(z / H)$ for different liquids; $A 315$ (lower) - RT (upper); a) $w_{\text {og }}=0$; b) $w_{\text {og }}=5.1 \cdot 10^{-3} \mathrm{~m} \mathrm{~s}^{-1}$; - distilled water; $\mathrm{O}$ - electrolyte; + - $30 \%$ aqueous solution of glucose; points - thermal method; solid line-electrochemical method

the measurement series (at given levels of $z / H$ and $w_{\text {og }}$ values). The value $A=0.65 \pm 0.09$ was obtained independently on the level of axial coordinate $z / H$ for the turbulent flow of the distilled water and 30 $\%$ aqueous solution of glucose as continuous phases. The value $A=0.67^{3}$ was assumed in further analysis of the heat transfer coefficients within this region of the fluid flow. For the transitional flow of the glycerol as a continuous phase, lower value of the exponent at Reynolds number $A=0.58 \pm 0.05$ was obtained and used in further calculations.

Experimental data presented in Figs. $5-8$ were obtained by means of the local heat source, which was built at the vessel wall at height $z$. This measuring thermal method enabled determination of $\alpha$ coefficient at seven different axial positions $z$. Because sensors in an electrochemical method were substantially smaller then it was possible to arrange axially 22 cathodes in the range $z / H \in(0 ; 1)$. Therefore, much more detailed distributions of the $\alpha=\mathrm{f}(z / H)$ functions were obtained.

An example of the dimensionless axial distributions of the heat transfer coefficient $N u / \mathrm{Pr}^{0.33}=$ $\mathrm{f}(z / H)$ is presented in Fig. 9. These profiles illustrate the results obtained for the turbulent fluid flow and a given value of the $R e=$ const, an electrolyte as liquid phase without $\left(w_{\mathrm{og}}=0\right)$ or with air $\left(w_{\mathrm{og}}=\right.$ $5.1 \cdot 10^{-3} \mathrm{~m} \mathrm{~s}^{-1}$ ) introduced to the system. The profiles in Fig. 9a, gained by means of the electrochemical method, reveal much more detail compared to the distributions shown in Figs. $4 \mathrm{a}$ and $4 \mathrm{~b}$, which were obtained using thermal method. At first, two local maximums are visible on the level of the blades of the upper Rushton turbine. Moreover, the shape of the profiles in the region of both impellers reflects fluid circulation imposed by the upper radial flow Rushton turbine and lower down-pumping A 315 impeller. Rushton turbine operating in the upper part of the agitated vessel enables much higher values of the local heat transfer coefficient than does the A 315 impeller operating in the lower part of the vessel. This conclusion concerns both liquid phase (Fig. 9a) and gas-liquid systems (Fig. 9b) agitated. Comparison of the profiles in Figs. $9 \mathrm{a}$ and $9 \mathrm{~b}$ shows observable effect of the gas phase on the decrease in the values of the local heat transfer coefficient.

The experimental results of the local heat transfer coefficient obtained by means of both thermal and electrochemical methods are compared in the form of the dimensionless function $N u /\left(\operatorname{Re}^{0.67} \operatorname{Pr}^{0.33} V i^{0.14}\right)=\mathrm{f}(z / H)$ in Fig. 10. In Fig. 10a, local values of the heat transfer coefficient are given for different liquids: distilled water, $30 \%$ aqueous solution of glucose (thermal method, points) and electrolyte (electrochemical method, empty circle, solid line), whereas Fig. 10b presents analogous data for the air-liquid system. Experimental data shown in Fig. 10a and $\mathrm{b}$ for liquids and gas-liquid systems are consistent, meaning that the measuring methods used in this study, in practice, had no effect on the measurement results.

Distributions of the heat transfer coefficient along the whole height of the cylindrical wall of the agitated vessel, obtained by means of both thermal and electrochemical methods, were approximated using the following equation

$$
N u=\left[\frac{\alpha T_{\mathrm{o}}}{\lambda}\right]=C \operatorname{Re}^{A} \operatorname{Pr}^{0.33} V i^{0.14} f_{1}(z / H) f_{2}\left(F r_{\mathrm{g}}\right)
$$

In Eq. (12), the value of exponent $A$ is 0.67 for turbulent range of the fluid flow $\left(10^{4}<\operatorname{Re}<9 \cdot 10^{4}>\right)$, and $A$ is 0.58 for the transitional range of the flow 
Table 1 - Functions $C f f_{2}$ in Eq. (12) for gas-liquid systems agitated using two impellers on a common shaft (A 315 (lower) - RT (upper)); turbulent range of the fluid flow $\left(10^{4}<\operatorname{Re}<9 \cdot 10^{4} ; 6.4<\operatorname{Pr}<21.5 ; 0<\mathrm{Fr}_{g}<1.27 \cdot 10^{-5}\right)$

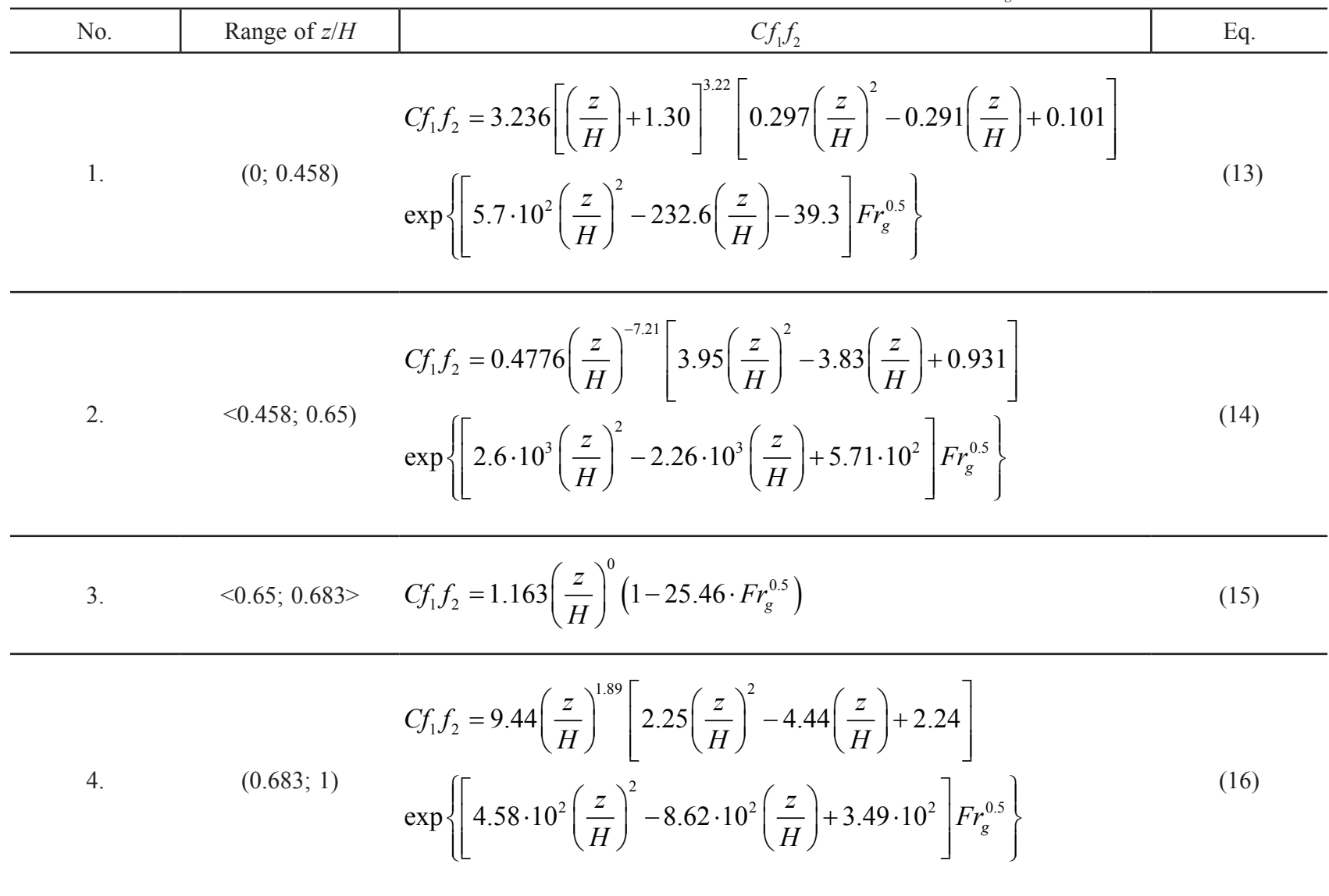

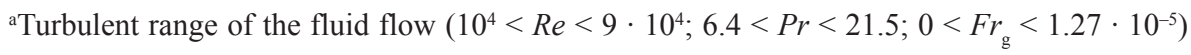

$(70<\operatorname{Re}<560)$. Dimensionless axial coordinate $z / H$ changes from 0 to 1 . Froude number for gas phase, defined as $\mathrm{Fr}_{\mathrm{g}}=w_{\mathrm{og}}{ }^{2} /(\mathrm{gT})$, describes the effect of the superficial gas velocity $w_{\mathrm{og}}$ on the value of the heat transfer coefficient. Functions $f_{1}$ and $f_{2}$ have different form depending on the ranges of the $z / H$ and fluid flow. Functions $C f_{1} f_{2}$ in Eq. (12) are collected in Tables 1 and 2. Equations (13) - (16) describe the experimental data, within the turbulent range of the fluid flow $\left(10^{4}<\operatorname{Re}<9 \cdot 10^{4} ; 6.4<P r\right.$ $\left.<21.5 ; 0<F_{\mathrm{g}}<1.27 \cdot 10^{-5}\right)$. Equations (17) $-(21)$ describe the results within the transitional range of the fluid flow $(70<\operatorname{Re}<560 ; 1766<\operatorname{Pr}<2260$; $\left.0<F r_{\mathrm{g}}<9.21 \cdot 10^{-6}\right)$.

Equations collected in Tables 1 and 2 show that function $f_{1}$ depends only on the dimensionless axial coordinate $z / H$. The function $f_{2}$ is more complicated because, with the exception of the region ascribed to the position of the upper impeller (Rushton turbine), it takes into account both effects of superficial gas velocity $w_{\mathrm{og}}$ and geometrical parameter $z / H$ on the local heat transfer coefficient.

On the basis of the equations given in Tables 1 and 2, the profiles of the heat transfer coefficient were calculated in the form of the function $\mathrm{Nu}$
$\operatorname{Re}^{A} \operatorname{Pr}^{0.33} \mathrm{Vi}^{0.14}=C f_{f_{2}}=\mathrm{f}(z / H)$. These distributions are compared in Figs. 11 and 12 with the experimental data obtained for the different liquids (distilled water, aqueous solution of glucose, electrolyte and glycerol) and both systems without $\left(w_{\mathrm{og}}=0\right.$, Figs. $11 \mathrm{a}, 12 \mathrm{a})$ and with gas phase $\left(w_{\mathrm{og}}=3.4^{\mathrm{og}} \cdot 10^{-3}\right.$ $\mathrm{m} \mathrm{s}^{-1}$, Figs. 11b, 12b). Both calculated (solid line) and experimental (points) results presented in Figs. 11 (turbulent flow) and 12 (transitional flow) are consistent. This means that the equations given in Tables 1 and 2 approximate experimental data with good accuracy. Mean relative errors of both sets of equations, (13) - (16) and (17) - (21), corresponding to turbulent and transitional ranges of the fluid flow, are $+12 \%$ and $+13 \%$, respectively. Comparison of the experimental data and those calculated from proposed equations, expressed in the form of the $C_{1} f_{1} f_{2}$, shows sufficient consistency of the results for both turbulent (Fig. 13a) and transitional (Fig. $13 \mathrm{~b}$ ) ranges of the fluid flow in the agitated vessel.

Comparison of three different configurations of two high-speed impellers on a common shaft, i.e., $\mathrm{RT}-\mathrm{RT}^{25}$, CD $6-\mathrm{RT}^{22}$ and A 315 - RT, shows that the type of lower impeller (RT, CD 6 or A 315) has decisive effect on the intensity of the heat transfer 
Table 2 - Functions $C f f_{2}$ in Eq. (12) for gas-liquid systems agitated using two impellers on a common shaft (A 315 (lower) - RT (upper)); transitional range of the fluid flow $\left(70<\operatorname{Re}<560 ; 1766<\operatorname{Pr}<2260 ; 0<\mathrm{Fr}_{g}<9.21 \cdot 10^{-5}\right)$

\begin{tabular}{|c|c|c|c|}
\hline No. & Range of $z / H$ & $C f_{1} f_{2}$ & Eq. \\
\hline 1. & $(0 ; 0.28)$ & $\begin{array}{l}C f_{1} f_{2}=2.167\left[\left(\frac{z}{H}\right)+3.186\right]^{-2.21}\left[-50.43\left(\frac{z}{H}\right)^{2}-29.35\left(\frac{z}{H}\right)+27.02\right] \\
\exp \left\{\left[-6 \cdot 10^{2}\left(\frac{z}{H}\right)^{2}+2.21 \cdot 10^{2}\left(\frac{z}{H}\right)-25.66\right] F r_{g}^{0.25}\right\}\end{array}$ & (17) \\
\hline 2. & $<0.28 ; 0.42)$ & $\begin{array}{l}C f_{1} f_{2}=0.0429\left(\frac{z}{H}\right)^{-0.09}\left[-19.445\left(\frac{z}{H}\right)^{2}+2.935\left(\frac{z}{H}\right)+43.532\right] \\
\exp \left\{\left[8.244\left(\frac{z}{H}\right)^{2}+12.45\left(\frac{z}{H}\right)-13.72\right] F r_{g}^{0.23}\right\}\end{array}$ & (18) \\
\hline 3. & $<0.42 ; 0.65)$ & $\begin{array}{l}C f_{1} f_{2}=11.02\left(\frac{z}{H}\right)^{1.11}\left[26.55\left(\frac{z}{H}\right)^{2}-27.66\left(\frac{z}{H}\right)+7.38\right] \\
\exp \left\{\left[66.66\left(\frac{z}{H}\right)^{2}-41.75\left(\frac{z}{H}\right)-3.85\right] F r_{g}^{0.26}\right\}\end{array}$ & (19) \\
\hline 4. & $<0.65 ; 0.683>$ & $C f_{1} f_{2}=4.28\left(\frac{z}{H}\right)^{0}\left(1-2.19 \cdot F r_{g}^{0.244}\right)$ & (20) \\
\hline 5. & $(0.683 ; 1)$ & $C f_{1} f_{2}=1.151\left(\frac{z}{H}\right)^{-3.45} \exp -5.66 \cdot 10^{-4}\left(\frac{z}{H}\right)^{-23.37} F r_{g}^{0.29}$ & $(21)$ \\
\hline
\end{tabular}

${ }^{a}$ Transitional range of the fluid flow $\left(70<R e<560 ; 1766<\operatorname{Pr}<2260 ; 0<F r_{\mathrm{g}}<9.21 \cdot 10^{-5}\right)$
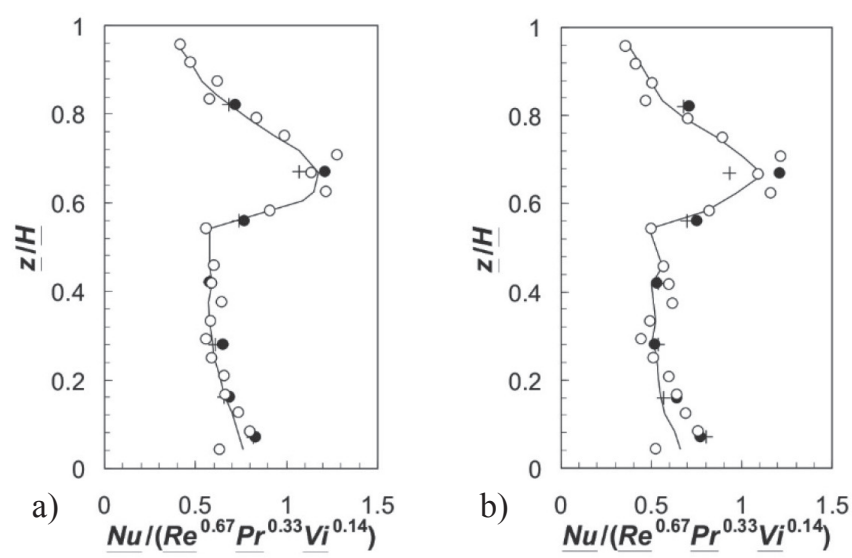

Fig. 11 - Comparison of the experimental (points) and calculated (solid line) values of the function $\left[\mathrm{Nu} /\left(\mathrm{Re}^{0.67} \mathrm{Pr}^{0.33} \mathrm{Vi}^{0.14}\right)\right]$ $=C f_{1}=f(z / H)$ for the system with A 315 (lower) $-R T$ (upper) impellers; air - liquid system; turbulent range of the fluid flow; a) $w_{o g}=0 \mathrm{~m} \mathrm{~s}^{-1}$; b) $w_{\mathrm{og}}=3.4 \cdot 10^{-3} \mathrm{~m} \mathrm{~s}^{-1}$; - distilled water; - electrolyte; $+-30 \%$ aqueous solution of glucose
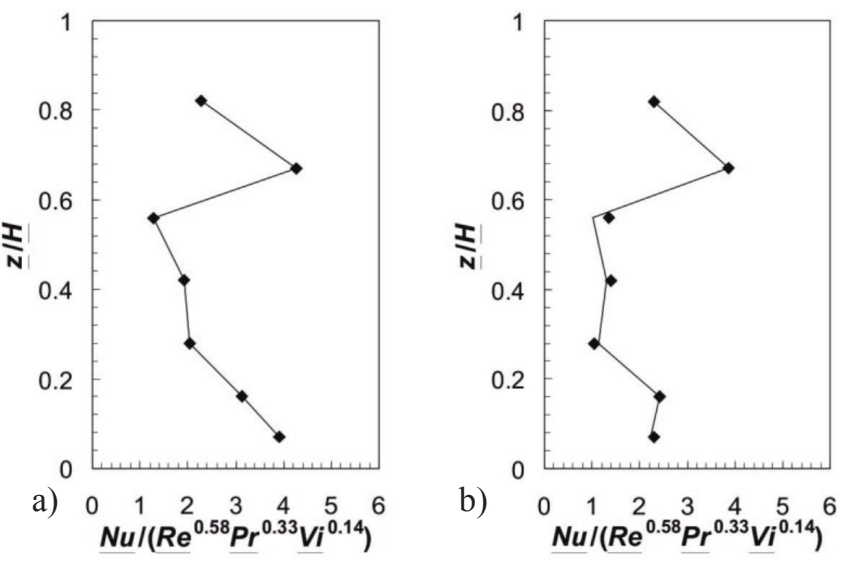

Fig. 12 - Comparison of the experimental (points) and calculated (solid line) values of the function $\left[\mathrm{Nu} /\left(\mathrm{Re}^{0.58} \mathrm{Pr}^{0.33} \mathrm{Vi}^{0.14}\right)\right]$ $=C f_{1} f_{2}=f(z / H)$ for the system with A 315 (lower) - RT (upper) impellers; air - glycerol system; transitional range of the fluid flow; a) $w_{\text {og }}=0 \mathrm{~m} \mathrm{~s}^{-1}$; b) $w_{\text {og }}=3.4 \cdot 10^{-3} \mathrm{~m} \mathrm{~s}^{-1} ;-$ glycerol 
a)

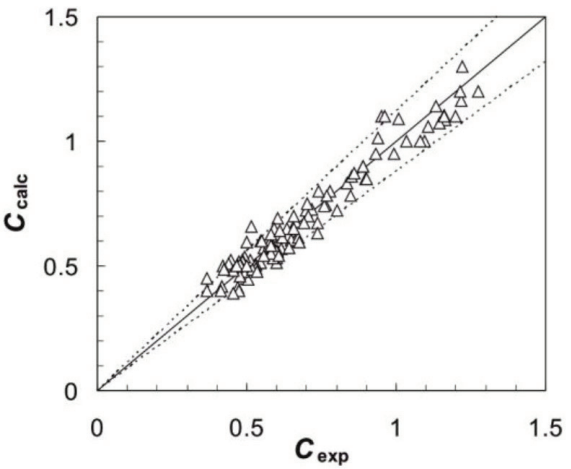

b)

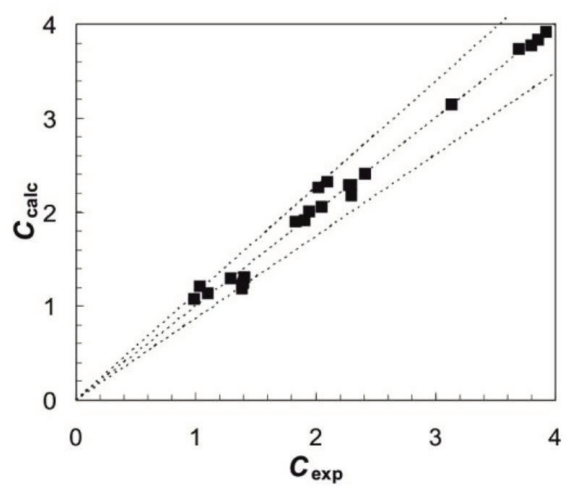

Fig. 13 - Comparison of the $C_{1} f_{1} f_{2}$ values obtained experimentally and calculated from Eqs. (13) - (21) for gas - liquid systems; a) turbulent range of the flow (liquid phase: distilled water; $30 \%$ aqueous solution of glucose, electrolyte); b) transitional range of the flow (liquid phase: glycerol)

process in the zone of its action. For example, in relation to the radial flow lower Rushton turbine and axial coordinate $z / H=0.17$, local heat transfer coefficients are $81 \%$ and $54 \%$ only for CD 6 and A 315 impellers, respectively, within the turbulent regime of the fluid flow. In case of the choice of the lower high-speed impeller, a compromise should be considered between Rushton turbine (radial flow, high intensity of heat transfer and high shear stresses), CD 6 impeller (radial flow, lower heat transfer intensity and shear stresses but good gas dispersion), and A 315 impeller (down-pumping, relatively low heat transfer intensity, low shear stresses and recommendation for mixing in bioprocesses).

\section{Conclusions}

The results of the experimental investigation of the local heat transfer process near the wall region of the jacketed baffled vessel, equipped with an A 315 - RT impeller system, were obtained for coalescing and non-coalescing air-Newtonian liquid systems within the turbulent and transitional regimes of the fluid flow. These results, including approx. two thousands experimental data, may be summarized as follows:
1. The distributions of the heat transfer coefficient are strongly differentiated on the vessel wall and significantly depend on the position of the measuring point on the vessel wall (axial coordinate $z / H)$ as well as $R e, P r$ and $F r_{\mathrm{g}}$ numbers.

2. Fluid circulation imposed by both impellers on the common shaft affects the local values of the heat transfer coefficient. The highest values of the local coefficient $\alpha$ correspond to the level of the radial flow upper Rushton turbine $(z / H=0.67)$. Compared to lower down-pumping A 315 impeller at the position $z / H=0.17$, for turbulent and transitional regimes of the fluid flow, these values are higher by $73 \%$ and $39 \%$, respectively. The increase in the superficial gas velocity in the system causes the diminution of the local heat transfer coefficients.

3 . The distributions of the heat transfer coefficient were approximated mathematically by means of dimensionless Eqs. (12) - (21) as the function of the $z / H, R e, P r$ and $F r$ numbers. The equations (13) - (16) and (17) - (2⿺ 丶 1$)$ have no equivalent in the open literature.

\section{Nomenclature}

\begin{tabular}{|c|c|c|}
\hline & - length of impeller blade, & $\mathrm{m}$ \\
\hline$B$ & - width of baffle, & $\mathrm{m}$ \\
\hline$b$ & - width of impeller blade, & $\mathrm{m}$ \\
\hline C & - constant in Nusselt equation & \\
\hline$C_{\mathrm{A}}$ & $\begin{array}{l}\text { - concentration of component A } \\
\text { in electrolyte, }\end{array}$ & $\mathrm{kmol} \mathrm{m}^{-3}$ \\
\hline$C_{\mathrm{m}}$ & - constant in Eq. (1) & \\
\hline$C$ & - constant in Eq. (2) & \\
\hline$c_{p}$ & - specific heat at constant pressure, & $\mathrm{J} \mathrm{kg}^{-1} \mathrm{~K}^{-1}$ \\
\hline$D$ & - impeller diameter, & $\mathrm{m}$ \\
\hline$D_{\mathrm{A}}$ & - diffusion coefficient, & $\mathrm{m}^{2} \mathrm{~s}^{-1}$ \\
\hline$d_{\mathrm{d}}$ & - sparger diameter, & $\mathrm{m}$ \\
\hline$d_{\mathrm{o}}$ & - disc diameter, & $\mathrm{m}$ \\
\hline . & $\begin{array}{l}\text { - clearance between gas sparger } \\
\text { and vessel bottom, }\end{array}$ & $\mathrm{m}$ \\
\hline$F$ & - Faraday's constant & \\
\hline$g$ & - acceleration due to gravity, & $\mathrm{m} \mathrm{s}^{-2}$ \\
\hline$H$ & - liquid height in agitated vessel, & $\mathrm{m}$ \\
\hline$h_{1}, h_{2}$ & $\begin{array}{l}\text { - distance of impellers from } \\
\text { vessel bottom, }\end{array}$ & $\mathrm{m}$ \\
\hline$I_{\mathrm{d}}$ & - diffusion current, & A \\
\hline$J$ & - number of baffles & \\
\hline$K$ & - constant in Eq. (2) & \\
\hline$k_{\mathrm{A}}$ & - mass transfer coefficient, & $\mathrm{m} \mathrm{s}^{-1}$ \\
\hline$l_{1}$ & - distance between thermocouples, & $\mathrm{m}$ \\
\hline
\end{tabular}


$l_{2} \quad-$ distance between front thermocouple and contact surface of heat flux meter with liquid,

$\mathrm{m}$

- impeller speed,

$\mathrm{s}^{-1}$

$n$

- power consumption,

W

$p_{\text {corr }} \quad-$ correction factor in Eq. (9)

$q_{\mathrm{w}} \quad-$ heat flux

$\mathrm{W} \mathrm{\textrm {m } ^ { - 2 }}$

- radius of measuring element,

m

- surface area of cathode,

$\mathrm{m}^{2}$

- inner diameter of agitated vessel, $\mathrm{m}$

- temperature,

$\mathrm{m}$

- mean temperature of agitated liquid, $\mathrm{K}$

- temperature of vessel wall,

$\mathrm{K}$

- liquid volume in Eq. (2),

$\mathrm{m}^{3}$

- gas flow rate,

$\mathrm{m}^{3} \mathrm{~s}^{-1}$

- superficial gas velocity,

$\mathrm{m} \mathrm{s}^{-1}$

- number of impeller blades

- axial coordinate,

$\mathrm{m}$

- number of electrons taking part in reaction

\section{Greek symbols}

$\alpha \quad-$ local heat transfer coefficient, $\quad \mathrm{W} \mathrm{m} \mathrm{m}^{-2} \mathrm{~K}^{-1}$

$\beta-$ angle of impeller blade inclination, deg

$\eta \quad$ - dynamic viscosity of liquid, $\quad \mathrm{Pa} \mathrm{s}$

$\lambda-$ conductivity of liquid,

$\mathrm{W} \mathrm{m} \mathrm{m}^{-1} \mathrm{~K}^{-1}$

$\lambda_{1}-$ conductivity of stainless steel

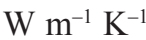

$v \quad-$ kinematic viscosity of liquid,

$\mathrm{m}^{2} \mathrm{~s}^{-1}$

$\rho \quad-$ liquid density,

$\mathrm{kg} \mathrm{m}^{-3}$

\section{Subscripts}

$$
\begin{array}{ll}
\text { anal } & \text { - analogy } \\
\mathrm{m} & - \text { averaged value } \\
\mathrm{w} & - \text { wall }
\end{array}
$$

\section{Dimensionless groups}

$F r_{\mathrm{g}}-$ Froude number $\left(=\frac{w_{\mathrm{og}}^{2}}{g T_{\mathrm{o}}}\right)$

$N u \quad-$ Nusselt number $\left(=\frac{\alpha T_{\mathrm{o}}}{\lambda}\right)$

$\operatorname{Pr} \quad-$ Prandtl number $\left(=\frac{c_{p} \eta}{\lambda}\right)$

Re - Reynolds number $\left(=\frac{n D^{2} \rho}{\eta}\right)$

Sc - Schmidt number $\left(=\frac{v}{D_{\mathrm{A}}}\right)$

$V i \quad-$ Simplex viscosity $\left(=\frac{\eta}{\eta_{\mathrm{w}}}\right)$

\section{References}

1. Kurpiers, $P$., Waermeuebertragung in Ein- und Mehrphasen Reaktoren, VCH, Weinheim, 1985.

2. Nagata, S., Mixing: Principles and Applications, Kodansha, Tokyo, 1975.

3. Stręk, F., Mixing and Agitated Vessels (in Polish), WNT, Warsaw, 1981.

4. Karcz, J., Studies of heat transfer process in agitated vessels, Trends in Chemical Engineering 8 (2003) 161.

5. Mohan, P., Emery, N., Al-Hassan, A., Review heat transfer to Newtonian fluids in mechanically agitated vessels, Exp. Therm. Fluid Sci. 5 (1992) 861. doi: https://doi.org/10.1016/0894-1777(92)90130-W

6. Cudak, M., Major-Godlewska, M., Karcz, J., Problems of heat transfer in agitated vessels, Practical Aspects of Chemical Engineering, Springer International Publishing AG, part of Springer Nature 2018, pp. 35-50. doi: https://doi.org/10.1007/978-3-319-73978-6_3

7. Niedzielska, A., Kuncewicz, Cz., Heat transfer and power consumption for ribbon impellers. Mixing efficiency, Chem. Eng. Sci. 60 (2005) 2439.

doi: https://doi.org/10.1016/j.ces.2004.10.046

8. Delaplace, G., Demeyre, J. F., Guerin, R., Debreyne, P., Leuliet, J. C., Determination of representative and instantaneous process side heat transfer coefficients in agitated vessel using heat flux sensors, Chem. Eng. Process. 44 (2005) 993. doi: https://doi.org/10.1016/j.cep.2004.11.005

9. Delaplace, G., Torrez, C., Leuliet, J. C., Belaubre, N., Andre, $C$., Experimental and CFD simulation of heat transfer to highly viscous fluids in an agitated vessel equipped with a non standard helical ribbon impeller, Trans IChemE $\mathbf{7 9}$ (2001) Part A 927.

10. Rai, C. L., Devotta, I., Rao, P. G., Heat transfer to viscous Newtonian and non-Newtonian fluids using helical ribbon agitator, Chem. Eng. J. 79 (2000) 73. doi: https://doi.org/10.1016/S1385-8947(00)00169-8

11. Triveni, B., Vishwanadham, B., Venkatesshwar, S., Studies on heat transfer to Newtonian and non-Newtonian fluids in agitated vessel, Heat Mass Transfer. 44 (2008) 1281. doi: https://doi.org/10.1007/s 00231-007-364-2.

12. Broniarz-Press, L., Różańska, S., Determination of the flow and heat transfer characteristics in non-Newtonian media agitated using the electrochemical technique, Int. J. Heat Mass Transf. 51 (2008) 910.

doi: https://doi.org/10.1016/j/ijheatmasstransfer.2007.11.003

13. Wang, $K$., Yu, S., Heat transfer and power consumption of non-Newtonian fluids in agitated vessels, Chem. Eng. Sci. 44 (1989) 33. doi: https://doi.org/10.1016/0009-2509(89)85229-7

14. Wichterle, K., Heat transfer in agitated vessels, Chem. Eng. Sci. 49 (1994) 1480. doi: https://doi.org/10.1016/0009-2509(94)85075-5

15. Jagadeesh Babu, P. E., Heat transfer studies in agitated vessel using immiscible liquid mixtures, National Journal on ChemBiosis 1 (2010) 5.

16. Perarasu, V. T., Arivazhagan, M., Sivashanmugam, P., Heat transfer characteristics of $\mathrm{TiO}_{2} /$ water nanofluid in a coiled agitated vessel provided with disc turbine agitator, Chem. Eng. Commun. 200 (2013) 783. doi: https://doi.org/10.1080/00986445.2012.722148

17. Cudak, M., Karcz, J., Distribution of local heat transfer coefficient values in the wall region of an agitated vessel, Chem. Pap. 62 (2008) 92. doi: https://doi.org/10.2478/s11696-007-0084-6 
18. Fort, I., Placek, J., Strek, F., Jaworski, Z., Karcz, J., Heat and momentum transfer in the wall region of a cylindrical vessel mixed by a turbine impeller, Collect. Czech. Chem. Commun. 44 (1979) 684. doi: https://doi.org/10.1135/cccc19790684

19. Kanamori, H., Yamamoto, T., Kato, Y., Zamzam, Z., Characteristics of heat transfer coefficient distribution at inside wall of an agitated vessel based on data measured by using a new measuring method, J. Chem. Eng. Jpn. 44 (2011) 908. doi: https://doi.org/10.1252/jcej.11we043

20. Karcz, J., Cudak, M., Szoplik, J., Stirring of a liquid in a stirred tank with an eccentrically located impeller, Chem. Eng. Sci. 60 (2005) 2369. doi: https://doi.org/10.1016/j.ces.2004.11.018

21. Lu, W. M., Lan, C. M., Fang, H. W., Local heat transfer in a stirred vessel with and without aeration, J. Chem. Eng. Jpn. 28 (1995) 666. doi: https://doi.org/10.1252/jcej.28.666

22. Bielka, I., Cudak, M., Karcz, J., Local heat transfer process for a gas-liquid system in a wall region of an agitated vessel equipped with the system of CD 6 - RT impellers, Ind. Eng. Chem. Res. 53 (2014) 16539. doi: https://doi.org/10.1021/ie503003t

23. Haam, S., Brodkey, R. S., Fasano, J. B., Local heat transfer in a mixing vessel using heat flux sensors, Ind. Eng. Chem. Res. 31 (1992) 1384 doi: https://doi.org/10.1021/ie00005a020

24. Haam, S., Brodkey, R. S., Fasano, J. B., Local heat transfer in a mixing vessel using a high efficiency impeller, Ind. Eng. Chem. Res. 32 (1992) 575. doi: https://doi.org/10.1021/ie00015a022

25. Karcz, J., Studies of local heat transfer in a gas-liquid system agitated by double disc impellers in a slender vessel, Chem. Eng. J. 72 (1999) 217. doi: https://doi.org/10.1016/S1385-8947(99)00005-4

26. Karcz, J., Abragimowicz, A., Local heat transfer in a liquid and gas - liquid system agitated by concave disc turbine, in. van Akker, H. E. A. and Derksen J. J. (Eds.), $10^{\text {th }}$ European Conf. on Mixing, Elsevier Science B. V., Amsterdam, New York, pp.493-500, 2000. doi: https://doi.org/10.1016/B978-044450476-0/50062-5

27. Karcz, J., Abragimowicz, A., Local heat transfer in a solid-liquid system agitated by concave disc turbine in a jacketed vessel. $4^{\text {th }}$ International Symposium on Mixing in Industrial Processes, Toulouse, France, 14-16.05.2001.

28. Karcz, J., Cudak, M., Local momentum and heat transfer in liquid and gas-solid-liquid systems mechanically stirred in a jacketed vessel, Paper 24, $11^{\text {th }}$ European Conference on Mixing, Bamberg, Germany, 14-17.10.2003, pp. 447-454.

29. Zakrzewska, B., Jaworski, Z., CFD modeling of turbulent jacket heat transfer in a Rushton turbine stirred vessel, Chem. Eng. Technol. 27 (2004) 237. doi: https://doi.org/10.1002/ceat.200401988

30. Petera, K., Dostal, M., Jirout, T., Fort, I., Heat transfer similarities between impinging jets and axial-flow impellers, Theor. Found. Chem. Eng. 50 (2016) 937. doi: https://doi.org/10.1134/S0040579516060130

31. Fort, I., Hruby, M., Mosna, P., Studies on mixing. XXXVI. Axial high-speed rotary mixer as an axially symmetrical turbulent jet, Collection Czechoslov. Chem. Commun. 38 (1973) 1737. doi: https://doi.org/10.1135/cccc19731737

32. Bourne, J. R., Dossenbach, O., Post, T. A., Local and average mass and heat transfer generated by Pfaudler - type impellers, Paper 21, $5^{\text {th }}$ European Conference on Mixing, 1985, Wuerzburg, Germany.
33. Post, T. A., Geometrical influences on local and total mass and heat transfer in agitated tank, PhD Thesis, 1983, ETH No. 7249, Zurich, Switzerland.

34. Cudak, M., Domański, M., Szoplik, J., Karcz, J., An effect of the impeller eccentricity on the process characteristics in an agitated vessel - Experimental and numerical modeling, Theor. Found. Chem. Eng. 50 (2016) 922. doi: https://doi.org/10.1134/S0040579516060038

35. Devi, T. T., Kumar, B., Analyzing flow hydrodynamics in stirred tank with CD-6 and Rushton impeller, International Review of Chemical Engineering - Rapid Communication 3 (2011) 440.

36. Junker, H. J., Mann, Z., Hunt, G., Retrofit of CD-6 (Smith) impeller in fermentation vessels, Appl. Biochem. Biotechnol. 89 (2000) 67. doi: https://doi.org/10.1385/ABAB:89:1:67

37. Karcz, J., Bielka, I., Local heat transfer to gas-liquid system agitated in a jacketed reactor equipped with two impellers on the common shaft, Chem. Proc. Eng. 27 (2006) 1325.

38. Gelves, R., Dietrich, A., Takors, R., Modeling of gas-liquid mass transfer in a stirred tank bioreactor agitated by a Rushton turbine or a new pitched blade impeller, Bioproc. Biosyst. Eng. 7 (2014) 365. doi: https://doi.org/10.1007/s00449-013-1001-8

39. Gimbun, J., Rielly, C. D., Nagy, Z. K., Modelling of mass transfer in gas-liquid stirred tanks agitated by Rushton and CD-6 impeller: A scale-up study, Chem. Eng. Res. Des. 87 (2009) 437. doi: https://doi.org/10.1016/j.cherd.2008.12.017

40. Rielly, C. D., Evans, G. M., Davidson, J. F., Carpenter, K. $J$., Effect vessel scale-up on the hydrodynamics of a self-aerating concave blade impeller, Chem. Eng. Sci. 47 (1992) 3395. doi: https://doi.org/10.1016/0009-2509(92)85050-L

41. Sensel, M. E., Meyers, K. J., Fasano, J. B., Gas dispersion at high aeration rates in low to moderately viscous Newtonian liquids, process mixing: Chemical and biochemical applications, Part II, AIChE Symp. Series 89 (1993) 76.

42. Smith, J. M., Katsanevakis, A. N., Impeller power demand in mechanically agitated boiling systems, Chem. Eng. Res. Des. 71 (1993), Part A, 145.

43. Van't Riet, K., Boom, J. M., Smith, J. M., Power consumption impeller coalescence and recirculation in aerated vessels, Transactions of Institution of Chemical Engineers $\mathbf{5 4}$ (1976) 124.

44. Warmoeskerken, M. M. C. G., Smith, J. M., The hollow blade agitator for dispersion and mass transfer, Chem. Eng. Res. Des. 67 (1989) 193.

45. Panneerselvam, R., Savithri, S., Investigations on hydrodynamics and mass transfer in gas-liquid stirred reactor using computational fluid dynamics, Chem. Eng. Sci. 66 (2011) 3108 . doi: https://doi.org/10.1016/j.ces.2011.03.007

46. Zhengming, G., Yingchen, W., Yanmin, Z., Litian, S., Study on gas-liquid mass transfer characteristics in an agitated vessel. Part II. The effects of geometric parameters of an agitated tank on the volumetric mass transfer coefficient. In Proceedings of the 7th European Conference on Mixing, Part II, 315-320, Brugge, Belgium, 18-20.09. 1991.

47. Devi, T. T., Kumar, B., Comparison of flow patterns of dual Rushton and CD-6 impellers, Theor. Found. Chem. Eng. 47 (2013) 344-355. doi: https://doi.org/10.1134/S0040570513040210

48. Paul, E. L., Atiemo-Obeng, V. A., Kresta, S. M. (Eds), Handbook of Industrial Mixing, 2004, Wiley-Interscience, Inc. 
49. Tatterson, G. B., Fluid Mixing and Gas Dispersion in Agitated Tanks. McGraw-Hill, New York, 1991.

50. Karcz, J., Stręk, F., Bielka, I., Heat transfer efficiency for a gas-liquid system agitated in a jacketed vessel equipped with two impellers, Chem. Proc. Eng. 29 (2008) 713.

51. Kaminoyama, M., Watanabe, M., Nishi, K., Kamiwano, M., Numerical simulation of local heat transfer coefficients in stirred vessel with impeller for highly viscous fluids, J. Chem. Eng. Jpn. 32 (1999) 23.

doi: https://doi.org/10.1252/jcej.32.23
52. Bakker, A., A new gas dispersion impeller with vertically asymmetric blades, 2000, Published in "The Online CFM Book" at http://www.bakker.org/cfm

53. Machon, V., Fort, I., Antosova, E., Spanihel, B., Kudrna $V$., Gas flooding of an inclined blade impeller, Collection Czechoslov. Chem. Commun. 56 (1991) 636. doi: https://doi.org/10.1135/cccc19910636

54. Cudak, M., Karcz, J., Local momentum transfer process in a wall region of an agitated vessel equipped with an eccentric impeller, Ind. Eng. Chem. Res. 50 (2011) 4140. doi: https://doi.org/10.1021/ie/101977y 